\title{
Effects of anti-mite measures on children with mite-sensitive asthma: a controlled trial
}

\author{
M L BURR, B V DEAN, T G MERRETT, E NEALE, A S ST LEGER, AND \\ E R VERRIER-JONES
}

From the MRC Epidemiology Unit, Cardiff, the Asthma Research Unit, Sully Hospital, South Glamorgan, Rast Allergy Unit, Benenden Chest Hospital, Kent, and Llandough Hospital, South Glamorgan

ABSTRACT Mite counts and tests for mite antigen were performed on samples of dust taken from the bedding of 53 children with mite-sensitive asthma. The samples from damp houses and the beds of enuretic children had markedly more mites and mite-antigen than those from dry houses. Although the predominant species was usually Dermatophagoides pteronyssinus, some of the beds in the damp houses were heavily infested with another pyroglyphid mite Euroglyphus maynei, so that this was the species found in the greatest numbers. D pteronyssinus antigen was found to be $\vec{\varphi}$ correlated broadly with the total mite count, but more antigen was present for a given number of ${ }^{\infty}$ mites in the mattresses than in the blankets. The children were randomly allocated into two groups, one of which carried out rigorous anti-mite measures. The amounts of dust and mite antigen were reduced, though not the numbers of mites. Peak flow readings were monitored in the two groups $\frac{\bar{\partial}}{0}$ for eight weeks and a final assessment made by a paediatrician who was unaware of the allocation of each patient in the trial. No significant differences emerged in the progress of the two groups, $\stackrel{\triangleright}{\triangleright}$ both tending to improve. Measures designed to remove mites from bedding do not greatly benefit $\overrightarrow{0}$ the majority of children with mite-sensitive asthma.

There is a considerable body of evidence which suggests that the house-dust mite Dermatophagoides pteronyssinus is a major allergen in the provocation of allergic asthma. ${ }^{1-3}$ These mites are especially prolific in blankets and feather pillows and on the surface of mattresses. ${ }^{4-6}$ Sarsfield $e t \mathrm{al}^{7}$ reported that a group of children with mite-sensitive asthma improved considerably when measures were taken to remove mites from their bedding. Their study did not include a control group, however, so it cannot be known whether the improvement was spontaneous or psychosomatic rather than a response to the removal of provoking allergens. A randomised controlled trial was, therefore, undertaken to evaluate the effects of anti-mite procedures on children with mite-sensitive asthma.

\section{Subjects and methods}

Subjects for the trial were selected from among the children attending a paediatric outpatient clinic. They were all aged 4 years or over, with positive skin tests to $D$ pteronyssinus (weal size

Address for reprint requests: Dr M L Burr, MRC Epidemiology Un't. 4 Richmond Road, Cardiff CF2 3AS.
$2 \mathrm{~mm}$ or more), and they were currently suffering from asthma. Children whose asthma seemed $\vec{F}$ to be exacerbated by exposure to other allergens were excluded from the trial. After a full clinical $x$ assessment (including lung function testing) by a $\frac{0}{3}$ consultant paediatrician the subjects were randomly allocated to one of two groups. One group was visited by a nurse who started a programme of mite eradication directed mainly at the bed-우 ding and applied to all beds in the patients' bedrooms. The other patients formed the control group, who were also visited by the nurse N and given a "placebo" procedure in an attempt" to balance the possible effects of suggestion on 0 the "treated" group. Since the parents of asth- $\omega$ matic children are often aware of the relevance of dust and mites, any placebo procedure muste seem to them to be likely to confer benefit. $\Phi$ Sensitivity to house dust rather than to mites was, $\stackrel{+}{+}$ therefore, emphasised in this group, and the mothers given advice accordingly.

MITE ERADICATION MEASURES FOR

TREATED GROUP

The following seven measures comprised the programme of mite eradication. (1) The mattress 
was vacuum cleaned at start and at weekly intervals. (2) Blankets and sheets were laundered at start, and blankets beaten in open air at least once a fortnight. (3) Sheets, pillow-cases, and other washable bedding (including mattress-cover if present) were washed weekly. (4) Feather pillows were replaced by pillows with synthetic filling, or else enclosed in impervious cover, and pillows beaten weekly in open air. (5) Quilts and eiderdowns were removed unless less than six months old and washable. (6) Soft toys were removed if possible; otherwise they were washed, brushed, or vacuum-cleaned every week. (7) Carpets in bedroom were vacuum-cleaned several times every week, and upholstery vacuum-cleaned fortnightly.

\section{PLACEBO MEASURES FOR CONTROL GROUP}

The importance of visible and invisible dust in the living-room was emphasised in this group. Special dusters were issued, of a brand advertised as peculiarly effective in gathering dust. Spray-on polish was recommended for use before each dusting. The living-room was dusted daily using the special duster, and other rooms similarly dusted at least once a week. Upholstered chairs in living-room were vacuum-cleaned or brushed at least twice a week, and carpet in living-room was vacuum-cleaned daily.

\section{OBSERVATIONS AND MEASUREMENTS}

Each patient was issued with a peak flow gauge and the mother instructed in its use. They were asked to record three peak flow readings every morning and evening. The intervention procedures were applied after the first week so that baseline data could be obtained. After a further eight weeks the patients were reviewed in the asthma clinic by the paediatrician, who was unaware of their allocation within the trial. He then assessed their progress in the light of the mothers' report of symptoms and the changes in physical signs and lung function. No changes in treatment were made by the paediatrician until this second assessment had been made.

The mothers were also asked whether damp patches ever appeared on the walls of the house. Dust samples were obtained from the bedding of the treated group at the start of the trial, and from both groups at the end; the placebo group were left until the end for dust sampling so as to avoid drawing attention to the bedding at the start. The mattress and lower blankets were sampled uniformly for two minutes in two adjacent $10 \mathrm{~cm}$ squares near the centres of their upper and lower surfaces respectively using the suction device described by Blythe. ${ }^{4}$ In the treated group these areas were marked with cotton stitches; eight weeks later two further squares, adjacent to the first pair, were sampled in the same way. On each occasion one sample was examined for the presence of mites by the method of Rao et al. ${ }^{6}$

The other sample was submitted for estimation of $D$ pteronyssinus antigen, using an inhibitory RAST technique. Weighed amounts of dust samples were transferred into $20 \mathrm{ml}$ containers and the mite antigen was extracted overnight with $10 \mathrm{ml}$ of $0.2 \%$ albuminphosphate buffer, $\mathrm{pH} 7 \cdot 4$. After centrifugation the supernatant solutions were assayed. To standardise the assay, aliquots of $D$ pteronyssinus (Bencard Ltd) were used at dilutions ranging from 1 in 10 to 1 in 50000 , and $1 \mathrm{ml}$ of the tenfold dilution was arbitrarily assigned a mite antigen value of 1000 units. The assay procedure involved an overnight incubation of $100 \mu \mathrm{l}$ of test sample, or $D$ pteronyssinus standard, with $5 \mu 1$ of $D$ pteronyssinus reference serum pool-that is, sera from 25 patients with high titres of IgE antibodies specifically directed against the mite. Then $100 \mu l$ of $D$ pteronyssinus-cellulose particles ${ }^{8}$ were added to the mixture and incubated for three hours before centrifugation at $1500 \mathrm{~g}$ for two minutes and decanting the supernatant solution. Finally, 17 $\mathrm{nCi}$ of ${ }^{125}$ iodine anti-IgE in $100 \mu \mathrm{l}$. (Pharmacia GB Ltd) was added and, after overnight incubation, the particles were washed and their associated radioactivity measured in a gammacounter. The amounts of $D$ pteronyssinus antigen in the dust samples were interpolated from the standard reference curve; the more mite antigen present, the greater was the inhibition of reaction between the mite reference serum and the mite cellulose particles.

\section{Results}

\section{CHILDREN}

Fifty-five children were admitted to the trial, two of whom (both in the "treated" group) failed to keep regular peak flow records and were, therefore, excluded. The age and sex distribution of the remaining 53 is shown in Table 1. The trial was conducted over two years so that all seasons of the year were involved. In none of the subjects

Table 1 Subjects in the trial

\begin{tabular}{|c|c|c|c|c|c|c|}
\hline & \multirow{2}{*}{ Number } & \multicolumn{2}{|c|}{$\begin{array}{l}\text { Boys } \\
\text { Age }(y r)\end{array}$} & \multirow{2}{*}{ Number } & \multicolumn{2}{|c|}{$\begin{array}{l}\text { Girls } \\
\text { Age }(y r)\end{array}$} \\
\hline & & Mean & Range & & Mean & Range \\
\hline $\begin{array}{l}\text { Treated group } \\
\text { Placebo group }\end{array}$ & $\begin{array}{l}18 \\
18\end{array}$ & $\begin{array}{l}8 \cdot 7 \\
8 \cdot 9\end{array}$ & $\begin{array}{r}5-13 \\
4 \cdot 5-14\end{array}$ & $\begin{array}{l}8 \\
9\end{array}$ & $\begin{array}{l}9 \cdot 2 \\
9 \cdot 4\end{array}$ & $\begin{array}{l}5-14 \\
5-12\end{array}$ \\
\hline
\end{tabular}


Table 2 Peak flow readings of treated and control groups

* "PFR \%" = mean peak flow readings during trial expressed as percentage of mean peak flow readings over the previous three days.

was grass pollen an obvious precipitating cause of the asthma, but some did have positive skin tests to grass pollen as well as to mite extract, and they were not admitted to the trial during the grass pollen season.

The highest of the three peak flow readings each morning and evening was taken and mean values calculated for each subject for the period of the trial and expressed as percentages of the mean values for the previous three days. The coefficients of variation of each patient were also calculated separately for all the morning and evening readings during the trial. Table 2 shows the mean coefficients of variation for all the subjects in the two groups with the geometric means of the peak flow rate percentages. The coefficients of variation of the two groups are virtually identical, and the small difference between the PFR \% values does not achieve statistical significance.

Table 3 shows the assessment of the children by the paediatrician after discussion with their mothers and clinical examination. There was a general tendency for children in both groups to improve, but there was no obvious difference between the treated and control group.

\section{MITES}

The mite counts and mite antigen assays are

Table 3 Paediatrician's assessment of progress

\begin{tabular}{lllllll}
\hline & $\begin{array}{l}\text { Much } \\
\text { better }\end{array}$ & Better & Same & Worse & $\begin{array}{l}\text { Much } \\
\text { worse }\end{array}$ & Totals \\
\hline $\begin{array}{l}\text { Treated group } \\
\text { Placebo group }\end{array}$ & 6 & 11 & 8 & 2 & 0 & 26 \\
\hline
\end{tabular}

Table 4 Mite counts in the bedding of children in dry and damp houses

\begin{tabular}{llllll}
\hline \multirow{2}{*}{$\begin{array}{l}\text { Numbers } \\
\text { of mites }\end{array}$} & Blankets & \multicolumn{3}{l}{ Mattresses } \\
\cline { 2 - 3 } \cline { 5 - 6 } & Dry houses & Damp houses & & Dry houses & Damp houses \\
& & 3 & 1 & 4 & 1 \\
\hline 0 & 15 & 7 & 15 & 9 \\
$1-9$ & 6 & 14 & 6 & 14 \\
$10-99$ & 1 & 3 & 0 & 2 \\
$100-199$ & 0 & 3 & 0 & 2 \\
$200+$ & 25 & 28 & 25 & 28 \\
\hline Totals & 25 & & &
\end{tabular}

expressed throughout in terms of the $10 \mathrm{~cm} \overrightarrow{\vec{\omega}}$ square areas sampled rather than per gram of dust, since the latter figure is distorted by any heavy particles of dust which greatly increase the denominator.

The total numbers of mites found in the blankets and mattresses of the children are shown in table 4. Those houses in which damp patches? appeared on the inside walls (whether occasion- ally or permanently) were classified as damp, $\subseteq$ together with all those where the child was enuretic; all the rest were considered as dry. $\overrightarrow{0}$ There was an obvious tendency for damp houses. to have higher mite counts in both blankets ando mattresses. The distribution of mite counts wass extremely skew; the highest numbers found were 479 in a blanket and 2597 in a mattress.

As table 5 shows, in most samples the pre- $\frac{\mathbb{Q}}{Q}$ dominant species of mite was $D$ pteronyssinus, $\vec{\Rightarrow}$ but quite frequently this species was outnumbered의

Table 5 Predominant species of mites in children's bedding

\begin{tabular}{|c|c|c|c|c|}
\hline \multirow[t]{2}{*}{ Predominant species } & \multicolumn{2}{|c|}{ Blankets } & \multicolumn{2}{|c|}{ Mattresses } \\
\hline & $\begin{array}{l}\text { Dry } \\
\text { houses }\end{array}$ & $\begin{array}{l}\text { Damp } \\
\text { houses }\end{array}$ & $\begin{array}{l}\text { Dry } \\
\text { houses }\end{array}$ & $\begin{array}{l}\text { Damp } \\
\text { houses }\end{array}$ \\
\hline $\begin{array}{l}\text { D pteronyssinus } \\
\text { Euroglyphus maynei } \\
\text { Tarsonemus sp } \\
\text { No predominating species }\end{array}$ & $\begin{array}{r}15 \\
6 \\
0 \\
4\end{array}$ & $\begin{array}{r}13 \\
13 \\
0 \\
2\end{array}$ & $\begin{array}{r}12 \\
7 \\
0 \\
6\end{array}$ & $\begin{array}{r}15 \\
10 \\
2 \\
1\end{array}$ \\
\hline Totals & 25 & 28 & 25 & 28 \\
\hline
\end{tabular}

Table 6 Total numbers of mites found in samples $N$ from dry and damp houses

\begin{tabular}{|c|c|c|c|c|}
\hline & \multicolumn{2}{|c|}{ Blankets } & \multicolumn{2}{|c|}{ Mattresses } \\
\hline & $\begin{array}{l}\text { Dry } \\
\text { houses }\end{array}$ & $\begin{array}{l}\text { Damp } \\
\text { houses }\end{array}$ & $\begin{array}{l}\text { Drv } \\
\text { houses }\end{array}$ & $\begin{array}{l}\text { Damp } \\
\text { houses }\end{array}$ \\
\hline $\begin{array}{l}\text { Number of samples } \\
\text { Species of mites- }\end{array}$ & 25 & 28 & 25 & 28 \\
\hline D pteronyssinus & 279 & 557 & 126 & 418 \\
\hline Euroglyphus maynei & 163 & 1515 & 91 & 3077 \\
\hline Tarsonemus & 1 & 22 & 4 & 92 \\
\hline Cheyletus & 3 & 4 & 4 & 29 \\
\hline Glycyphagus & 3 & 6 & 3 & 4 \\
\hline Tyrophagus & 0 & 2 & 0 & 0 \\
\hline Acarus & $\mathbf{0}$ & 0 & 1 & 0 \\
\hline Gohiera fusca & 1 & $\mathbf{0}$ & 0 & $\mathbf{0}$ \\
\hline All mites & 450 & 2106 & 229 & 3620 \\
\hline
\end{tabular}


Table 7 Mite antigen in bedding of dry and damp houses

\begin{tabular}{llllll}
\hline $\begin{array}{l}\text { Mite } \\
\text { antigen } \\
\text { (units) }\end{array}$ & Blankets & \multicolumn{3}{l}{ Mattresses } \\
\cline { 2 - 3 } \cline { 5 - 5 } \cline { 5 - 5 } & Dry houses & Damp houses & Dry houses & Damp houses \\
\hline 1 & 14 & 6 & 7 & 3 \\
$1-9 \cdot 9$ & 7 & 12 & 4 & 6 \\
$10-19 \cdot 9$ & 3 & 4 & 8 & 4 \\
$20-99$ & 1 & 4 & 4 & 6 \\
$100+$ & 0 & 2 & 2 & 9 \\
\hline Totals & 25 & 28 & 25 & 28 \\
\hline
\end{tabular}

by another pyroglyphid mite, Euroglyphus maynei. This mite was sometimes present in large numbers and was responsible for the four heaviest infestations. No other species was found in comparable numbers; one mattress-sample contained 32 Tarsonemus mites and this was probably related to the fact that the bedroom ceiling was covered with black mould, since Tarsonemus seems to live on mould spores.

Table 6 shows the total numbers of the various species found in all the samples. Euroglyphus was especially prolific in the bedding of damp houses or where the child was enuretic, other species being favoured by dampness to a lesser extent.

The mite antigen results are shown in table 7 , similarly classified into dry and damp houses. It is clear that the blankets and mattresses in the damp houses contain more mite antigen than those in the dry houses.
The relationship between total mite counts and mite antigen is illustrated in figs 1 and 2 . In view of the skewed distribution of both variables a modified logarithmic scale was used, based on $\log (n+1)$ for mites and $\log$ (units +1$)$ for antigen, so as to accommodate zero values. There is a broad association between the numbers of mites and the amount of antigen in both blankets and mattresses, significant by Spearman's rank correlation test $(p<0.05$ for blankets; $p<0.01$ for mattresses). There seems to be more antigen for a given number of mites in the mattresses than there is in the blankets.

In table 8 the mite counts are shown separately for the placebo and treated groups, and the results for the latter group are shown before and after treatment. The anti-mite measures made very little difference to the mite counts in either the blankets or the mattresses. There was a

Table 8 Mite counts in bedding of control and treated groups

\begin{tabular}{|c|c|c|c|c|c|c|}
\hline \multirow{3}{*}{$\begin{array}{l}\text { Mite } \\
\text { counts }\end{array}$} & \multicolumn{3}{|l|}{ Blankets } & \multicolumn{3}{|c|}{ Mattresses } \\
\hline & \multirow{2}{*}{$\begin{array}{l}\text { Placebo } \\
\text { group }\end{array}$} & \multicolumn{2}{|c|}{ Treated group } & \multirow{2}{*}{$\begin{array}{l}\text { Placebo } \\
\text { group }\end{array}$} & \multicolumn{2}{|c|}{ Treated group } \\
\hline & & Before & After & & Before & After \\
\hline $\begin{array}{c}0 \\
1-9 \\
10-99 \\
100-99 \\
200+\end{array}$ & $\begin{array}{r}4 \\
12 \\
8 \\
2 \\
1\end{array}$ & $\begin{array}{r}0 \\
10 \\
12 \\
2 \\
2\end{array}$ & $\begin{array}{r}2 \\
12 \\
10 \\
1 \\
1\end{array}$ & $\begin{array}{r}2 \\
14 \\
10 \\
0 \\
1\end{array}$ & $\begin{array}{r}3 \\
10 \\
10 \\
2 \\
1\end{array}$ & $\begin{array}{r}2 \\
10 \\
11 \\
1 \\
2\end{array}$ \\
\hline Totals & 27 & 26 & 26 & 27 & 26 & 26 \\
\hline
\end{tabular}

Fig 1 Relationship between mite count and $D$ pteronyssinus antigen in blankets (for scale see text).

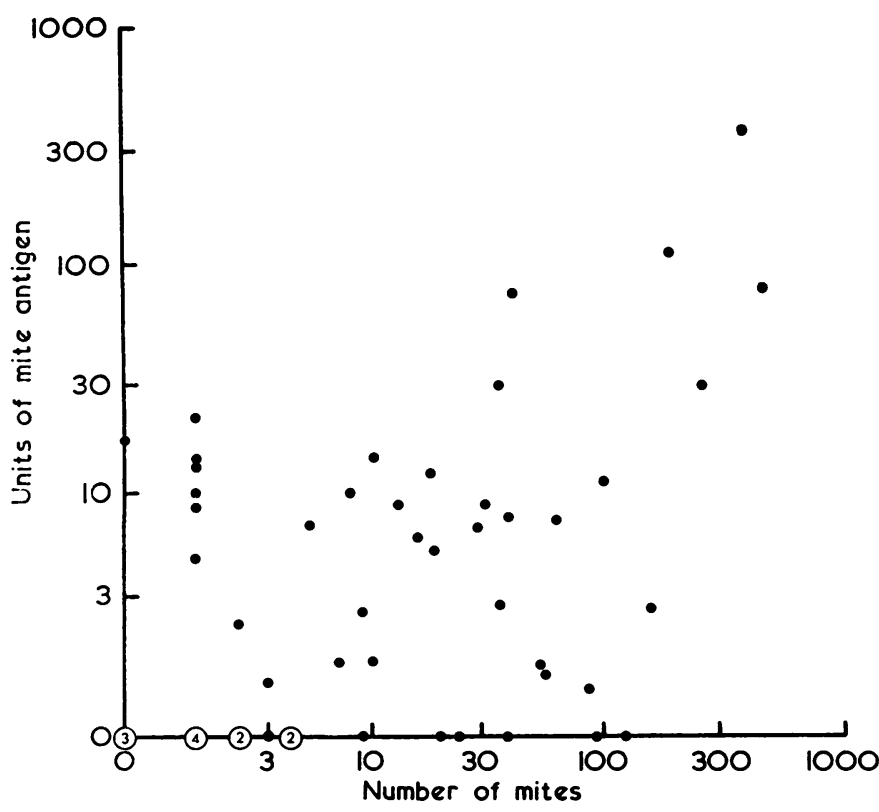

C 


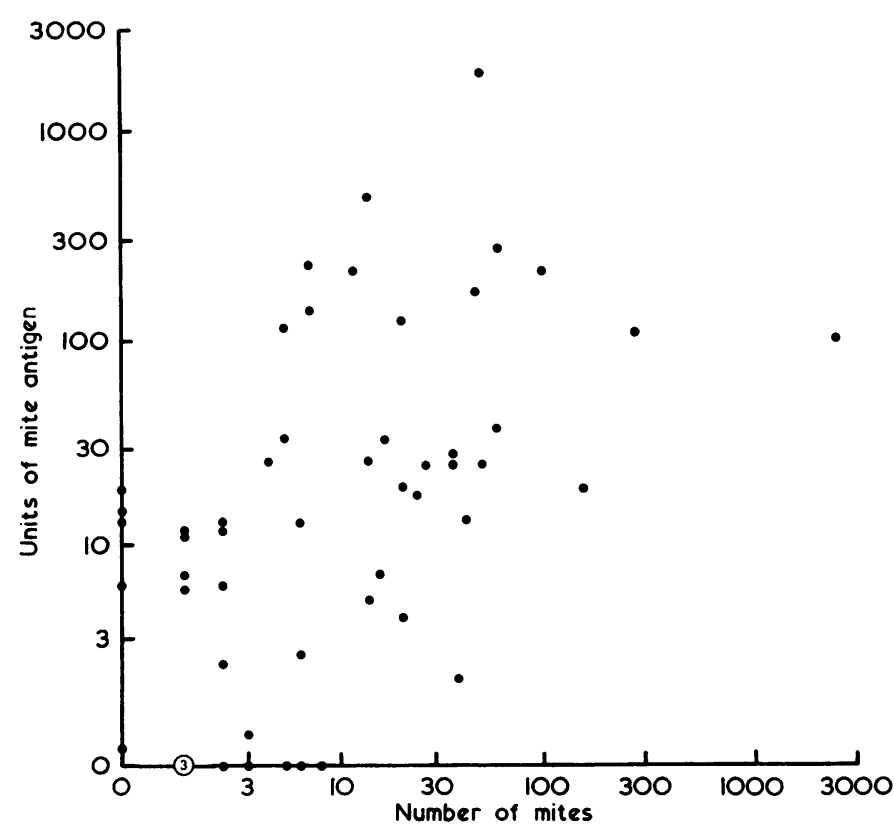

Fig 2 Relationship between mite coun $\stackrel{\vec{x}}{2}$ and $D$ pteronyssinus antigen in mattresse $w$ (for scale see text).

remarkable degree of consistency between the mite counts before and after treatment, both in respect of numbers of mites found and in regard to the predominant species of mites in each child's bedding.

Table 9 shows the amounts of mite antigen in the placebo and treated groups. There is a marked reduction in the amount of mite antigen obtained from the blankets and a rather less marked reduction in that obtained from the mattresses after the period of treatment.

In table 10 the weights of dust obtained from each $10 \mathrm{~cm}$ square are shown similarly classified. In view of the skewed distribution the data were transformed logarithmically and the geometric means are shown, in grams $\times 10^{-4}$. The weights of dust obtained from the placebo group were not markedly different from those obtained from the treated group; treatment produced a reduction in the amounts of dust, and a paired $t$ test

Table 9 Mite antigen in bedding of control and treated groups

\begin{tabular}{|c|c|c|c|c|c|c|}
\hline \multirow{3}{*}{$\begin{array}{l}\text { Mite } \\
\text { antigen } \\
\text { (units) }\end{array}$} & \multicolumn{3}{|l|}{ Blankets } & \multicolumn{3}{|c|}{ Mattresses } \\
\hline & \multirow{2}{*}{$\begin{array}{l}\text { Placebo } \\
\text { group }\end{array}$} & \multicolumn{2}{|c|}{ Treated group } & \multirow{2}{*}{$\begin{array}{l}\text { Placebo } \\
\text { group }\end{array}$} & \multicolumn{2}{|c|}{ Treated group } \\
\hline & & Before & After & & Before & After \\
\hline $\begin{array}{c}<1 \\
1-9.9 \\
10-19.9 \\
20-99 \\
100+\end{array}$ & $\begin{array}{r}12 \\
10 \\
4 \\
1 \\
0\end{array}$ & $\begin{array}{l}8 \\
9 \\
3 \\
4 \\
2\end{array}$ & $\begin{array}{r}15 \\
10 \\
0 \\
1 \\
0\end{array}$ & $\begin{array}{l}6 \\
8 \\
3 \\
5 \\
5\end{array}$ & $\begin{array}{l}4 \\
2 \\
9 \\
5 \\
6\end{array}$ & $\begin{array}{l}9 \\
6 \\
5 \\
4 \\
2\end{array}$ \\
\hline Totals & 27 & 26 & 26 & 27 & 26 & 26 \\
\hline
\end{tabular}

showed these reductions to be statistically signi ficant $(\mathrm{p}<0.05$ for blankets; $\mathrm{p}<0.01$ for mat tresses). Of the 26 beds, 19 showed a reduction in blanket dust and 20 showed a reduction in $\vec{b}$ mattress dust.

\section{Discussion}

It is widely believed that anti-mite measures areo beneficial to children with mite-sensitive asthma and their mothers are often advised accordingly. A recent book review in the Lancet ${ }^{10}$ castigated. the author for not recommending reduction of exposure to house-dust in mite-sensitive asthma tics. But the evidence for this belief seems to beo mostly anecdotal or derived from uncontrolleds studies. $^{7}$ In this trial we attempted to test the hypothesis that anti-mite measures in common

Table 10 Dust obtained from bedding of control and treated groups

\begin{tabular}{|c|c|c|c|c|c|c|}
\hline & \multicolumn{3}{|l|}{ Blankets } & \multicolumn{3}{|c|}{ Mattresses } \\
\hline & \multirow{2}{*}{$\begin{array}{l}\text { Placcbo } \\
\text { group }\end{array}$} & \multicolumn{2}{|c|}{ Treated group } & \multirow{2}{*}{$\begin{array}{l}\text { Placebo } \\
\text { group }\end{array}$} & \multicolumn{2}{|c|}{ Treated group } \\
\hline & & Before & After & & Before & After \\
\hline $\begin{array}{l}\text { Number of } \\
\text { subjects } \\
\text { Weight of dust } \\
(g \times 10-4) \\
\text { Geometric }\end{array}$ & 27 & 26 & 26 & 27 & 26 & 26 \\
\hline $\begin{array}{l}\text { Geometric } \\
\text { mean } \\
\text { Mean log } \\
\text { SE log }\end{array}$ & $\begin{array}{l}104 \\
2 \cdot 02 \\
0.08\end{array}$ & $\begin{array}{l}140 \\
2 \cdot 14 \\
0 \cdot 08\end{array}$ & $\begin{array}{c}90 \\
1 \cdot 76 \\
0.08\end{array}$ & $\begin{array}{l}569 \\
2 \cdot 75 \\
0 \cdot 10\end{array}$ & $\begin{array}{l}5) 2 \\
2 \cdot 77 \\
0 \cdot 10\end{array}$ & $\begin{array}{l}406 \\
2 \cdot 61 \\
0 \cdot 10\end{array}$ \\
\hline
\end{tabular}


use have an important clinical effect. It also enables some comparisons to be made between the relative importance of dampness and hygienic measures in determining the number of mites in the bedding of asthmatic children.

The results confirm the association between dampness and mite infestation which has been found in Holland ${ }^{1}$ and in London. ${ }^{11}$ It is seen in the mite counts and the mite antigen findings in both blankets and mattresses on a simple division between houses in which damp patches appear (or the child is enuretic) and the rest.

One rather surprising finding was the high prevalence of infestation with Euroglyphus maynei. This is a pyroglyphid mite which is antigenically similar to $D$ pteronyssinus. ${ }^{1}$ Since the heaviest infestations were caused by this mite it outnumbered even $D$ pteronyssinus in the overall count, although the latter was more often the predominant species found. Other species were present in far fewer numbers and the total mite count was, therefore, used as a basis for comparisons with estimations of $D$ pteronyssinus antigen. These comparisons show a broad association between the numbers of mites and the quantity of antigen in samples of dust from bedding, in contrast to the findings of Tovey and Vandenberg. ${ }^{12}$ A precise relationship would not be expected, since antigen is derived not only from living mites but also from their excreta and from particles of dead mites. The mattress dust seemed to contain more antigen for any given number of mites than the blanket dust, and this may reflect the tendency for debris of all kinds to collect on the surface of the mattress.

The subjects in this trial were all children who had been referred to a paediatrician because of their asthma. They were all sensitive to mites as judged by skin tests which have been shown to correlate fairly well with provocation tests and clinical history. ${ }^{13-14}$ It must be conceded that the children were not sensitive to mites alone. Some were sensitive to grass pollens, although this should not have been a confounding factor since their period in the trial was outside the pollen season. Furthermore the subjects had no clear seasonal history and no obvious precipitating causes other than mite allergy. Nevertheless it is possible that other allergies may have been operating. Perhaps a more rigidly selected group would show a response for measures of mite control.

One striking feature was the tendency of all subjects to improve, both in the treated and the control groups. This was shown in the rise which occurred in the mean peak flow readings and even more strikingly in the overall assessment, in which over half of each group reported an improvement. To some extent this improvement may be psychosomatic, or it may simply reflect the regression to the mean that occurs when any extreme group is followed up, since the children were probably referred to a consultant at a time when their asthma was especially troublesome. In any event it illustrates the need for objective measurements and a control group in any attempt to assess the treatment of asthma.

The degree of improvement in the two groups was very similar, and the coefficients of variation of the peak flow readings (used as an index of airflow variability) were virtually identical. Thus there is no evidence of any benefit specifically attributable to the hygienic measures employed. This is in accord with a crossover trial in adult patients, ${ }^{15}$ and another study using both subjective and objective measures of outcome. ${ }^{16}$ Similarly Warner ${ }^{17}$ reported that house mite avoidance benefited only seven out of 69 mitesensitive children, but he had no control subjects and it is not clear whether his criteria of improvement were subjective or objective.

The anti-mite measures used in the trial were fairly rigorous and the mothers of the treated patients seem to have carried out the instructions, since they achieved a reduction in dust weight and mite antigen. But the effect on the mite counts was negligible, suggesting that in. fested bedding can withstand efforts to expel the mites. In one damp house the mother was vacuum-cleaning the mattress daily before entry into the trial, yet the mite counts in the blanket and mattress were 262 and 14 respectively. The pillows of a subgroup of patients were also sampled, and some of these were heavily infested, confirming the findings of Wraith and Cunnington. ${ }^{5}$ Hughes and Maunsell ${ }^{18}$ reported a fall in the number of mites recovered from one mattress which was vacuum-cleaned at monthly intervals, and Cunnington and Gregory ${ }^{19}$ found fewer airborne mites during bedmaking after a mattress had been regularly vacuum-cleaned. But each of these studies involved one bed only and no control subjects were studied. The findings of the present trial suggest that in damp houses anti-mite procedures have little effect on the mites, while in most dry houses the bedding contains few mites anyway.

Presumably the reduction in mite antigen was insufficient to produce a markedly greater improvement than that which occurred spontaneously in the control group. It is arguable that the placebo procedure itself had some effect, but 
this is most unlikely, since living-room dust contains far fewer mites than bedroom dust. ${ }^{3}$ It is possible that these hygienic measures confer a small degree of improvement which might become more obvious in a longer trial, or that a subgroup of mite-sensitive patients may benefit to an important extent. But the overall results of applying anti-mite measures to the bedding of children with mite-sensitive asthma suggest that this procedure is not very rewarding.

We thank Dr CM Weaver for permission to include one of her patients in this trial. We also thank Dr DG Wraith for advice in planning the trial.

\section{References}

1 Voorhorst R, Spieksman FThM, Varekamp H. House dust atopy and the house dust mite. Leiden: Stafleu's Scientific Publishing Co, 1969.

2 Brown HM, Filer JL. Role of mites in allergy to house dust. Br Med J 1968; 3:646-7.

3 Maunsell K, Wraith DG, Cunnington AM. Mites and house-dust allergy in bronchial asthma. Lancet 1968; 1:1267-70.

4 Blythe ME. Some aspects of the ecological study of the house dust mite. Br J Dis Chest 1976; 70: 3-31.

5 Wraith DG, Cunnington AM. The mite and childhood asthma. Br Med J 1975; 3:766.

6 Rao VRM, Dean BV, Seaton A, Williams DA. A comparison of mite population in mattress dust from hospital and from private houses in Cardiff, Wales. Clin Allergy 1975; 5:209-15.
7 Sarsfield JK, Gowland G, Toy R, Norman ALE. Mite-sensitive asthma of childhood; trial of avoid ance measures. Arch Dis Child 1974; 49:716-21.

8 Merrett J, Merrett TG. RAST atopy screen. Clin Allergy 1978; 8:235-40.

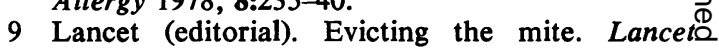
1974; 2:1492.

10 Lancet (book review). Allergy in children. Lancet 1979; 1:22.

11 Maunsell K, Hughes AM, Wraith DG. Mite asthma, cause and management. Practitioner 1970; 205:779-83.

12 Tovey E, Vandenberg R. Mite allergen content in commercial extracts and in bed dust deter- $-\omega$ mined by radio allergosorbent tests. Clin Allergy

13 British Thoracic and Tuberculosis Association. ㅇ Skin tests and clinical features of asthma. $\mathrm{Br}$ 里 Dis Chest 1975; 69:125-36.

14 Kerrebijn KF, Degenhart HJ, Hammers A. $\vec{c}$ Relation between skin tests, inhalation tests, an histamine release from leucocytes and IgE inhouse-dust mite allergy. Arch Dis Child 1976:00 51:252-8.

15 Burr ML, St Leger AS, Neale E. Anti-miteD measures in mite-sensitive adult asthma: a con trolled trial. Lancet 1976; 1:333-5.

16 Newton DAG, Maberley DJ, Wilson R. Housen dust mite hyposensitization. Br J Dis Chest 1978\% 72:21-8.

17 Warner JO. Mites and asthma in children. $B r \overrightarrow{\vec{F}}$ Dis Chest 1978; 72:79-87.

18 Hughes AM, Maunsell K. A study of a popula tion of housedust mite in its natural environment. Clin Allergy 1973; 3:127-31.

19 Cunnington AM, Gregory PH. Mites in bedroom air. Nature 1968; 217:1271-2. 